\title{
The R-R Interval and R-R Variability in Normal Infants During Sleep
}

\author{
GABRIEL (G. HADDAD, RALPH A. HESTEIN, MARY ANNE I. EPSTEIN. HEDI I.. LEISTNER, ANI) \\ ROBERT B. MLLLINS \\ Deparments of Pediatrics (Pulmonary Division) and Anesthesiologu. College of Phasicians and Surgeons, and \\ Department of Chemical Engineering and Applied Chemistr:. School of Engine'ering. Columbia University.
} New York. New York, USA

\section{Summary}

\begin{abstract}
Fighteen normal infants were studied in the first 2 wh of life uring sleep and subsequently at their monthly birthdays for the rst 4 months of life. The $R-R$ interval was measured with an ccuracy of $0.2 \mathrm{msec}$. Sleep staging was performed visually using lectroencephalogram, electrooculogram, and electromyogram, nd behavioral criteria. Our results show that the R-R interval and he beat-to-beat variability are, in general, smaller in rapid eye lovement than in quiet sleep. The two sleep states, however, are est differentiated by the overall variability which is characterisically higher in rapid eye movement sleep. The $R-R$ interval as ell as the overall and the beat-10-beat variability show minimal alues at 1 month and maximal rates of increase between 2 and 3 nonths of age, indicating that the $R-R$ interval and $R-R$ variability re not simple linear functions of age.
\end{abstract}

\section{Speculation}

We suspect that the large variability in the $R-R$ interval in rapid ve movement sleep is attributable to the wide fluctuations in the ictivity of the sympathetic and parasympathetic nervous system haracteristic of this sleep state. Because peripheral vasodilatation $s$ known to occur in rapid eye movement sleep. we speculate urther that the decrease in $R-R$ interval in rapid eye movement leep may be an adjustment to maintain the cardiac output and lood pressure.

Several studies performed in the fetus have suggested that a apid heart rate and a decreased heart rate variability are indicaive of fetal distress $(9,10,15,20)$. Indeed, monitoring of these unctions in clinical practice has improved neonatal outcome (15. 17).

We have recently described an infant who was found to have a rapid and fixed heart rate in early infancy and who died at the age of 5 months $(6)$. This suggested to us that heart rate and heart rate variability might also be a good index of well-being posinatally. With the exception of Harper 't al. (7), who studied heart rate and the overall variability of heart rate in infants in the first 6 months of life, there are little data on the maturation of the heart rate and heart rate variability in the first several months of life. Because the recognition of abnormal heart rate variability depends on the knowledge of both the overall and the beat-to-beat variabilities $(\triangle R R)$, we have studied both of these parameters along with the heart rate in a group of normal infants during the first 4 months of life. Inasmuch as heart rate and heart rate variability are under the control of the autonomic nervous system and inasmuch as the activity of this system varies with sleep state, we have performed our studies during both rapid eye movement (REM) and quiet sleep.
MATERIALS AND METHOISS

INFANT POPUIIATION

Eighteen normal, full-term infants were studied in the first $2 \mathrm{wk}$ of life (mean age, 9 days) and at 1. 2, 3, and 4 months of life. Because of imperfect parental compliance. the number of infants studied at each age varied from 12 to 18 . Pregnancy, vaginal delivery, and neonatal course were uneventful. There were 12 males and six females, and their birth weights ranged from 2700 to $4560 \mathrm{~g}$. Each study was performed after a usual midmorning feed and lasted for 2 to $3 \mathrm{hr}$. Skin temperature of these infants ranged between 35.5 and $37^{\circ} \mathrm{C}$ during the recording. None of the infants was on drugs. The infants are now six to 24 months old and have had normal growth and development. Physical examination including detailed neurologic examinations have been normal. Conventional 12-lead electrocardiograms (EC(i) performed at monthly intervals in the first four months of life were normal in all infants. Informed written consent was obtained from the parents of all infants.

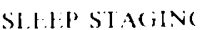

To stage sleep. three neurophysiologic signals were recorded on a polygraph. These were: (1) a $C_{1} A_{1}$ electroencephalogram; (2) a bipolar electrooculogram: and (3) a submental electromyogram. The resistance of these surface electrodes was below $10.000 \mathrm{ohms}$ Using these neurophysiologic signals and behavioral criteria. sleep staging was visually performed on 30 -sec periods by two independent observers $(1,4)$.

MLASIIRIMANT ()F THII R-R INTIRVAI.

Two standard electrocardiogram (EC $(j)$ electrodes were applied on the anterior chest of each infant. The position of these electrodes was chosen to get a single-peaked QRS complex. This aroided errors in accurately identifying the time of the QRS peak The EC $;$ was recorded on a polygraph and observed on an oscilloscope. The $R-R$ interval was measured by an electronic preprocessor with an accuracy of $0.2 \mathrm{msec}(12)$. Three steps were involved in this measurement. First, the QRS complex was identified by detecting when the filtered ECG exceeded a preset voltage threshold. Second. to prevent any phase shift errors. accurate localization of the highest peak of the $R$ wave was performed on the original, virtually unfiltered waveform (flat frequency response between 0.05 and $2000 \mathrm{~Hz}$ ). Last. the R-R interval was determined by measuring the time interval between the peak of one $R$ wave and the next. Fach $R-R$ interval was transferred in real time to a minicomputer through a direct memory access channel and stored on disc. The $\triangle R R$ or the absolute difference between one $R-R$ interval and the next was 
calculated subsequently. Artifactual R-R intervals were removed prior to analysis by (1) screening automatically for over and under range intervals, and (2) deleting from the data, after examining the original polygraph record. all the intervals that might have resulted from artifacts superimposed on the ECG signal. We analyzed 5,000 to $12,000 \mathrm{R}-\mathrm{R}$ intervals in each sleep state in each study; less than $\mathrm{I} / 1000 \mathrm{R}-\mathrm{R}$ intervals was rejected.

Three variables were analyzed: the mean $R-R$ interval, the interquartile range of the $R-R$ interval which measures the overall variability, and the interquartile range of the $\triangle R R$ which measures the beat-to-beat variability of the $R-R$ interval. The median and the interquartile range were used to describe our data because these statistics are unaffected by occasional extreme values or outliers. The median and the interquartile range values in each sleep state were then averaged. Statistical significance of the differences between these averages was determined by the nonparametric Sign Test and the Wilcoxon Rank Sum Test and by the Student $t$ test for paired variates. Differences were considered statistically significant when $P$ was less than 0.05 . Regression analysis was performed on the median $R-R$ interval and interquartile range of the $R-R$ interval and the $\triangle R R$ to study the maturational changes of the $R \cdot R$ interval and its variability.

\section{RESULTS}

Figures I through 4 summarize the sleep state and age-related differences in $R-R$ interval and overall and beat-to-beat variabil-

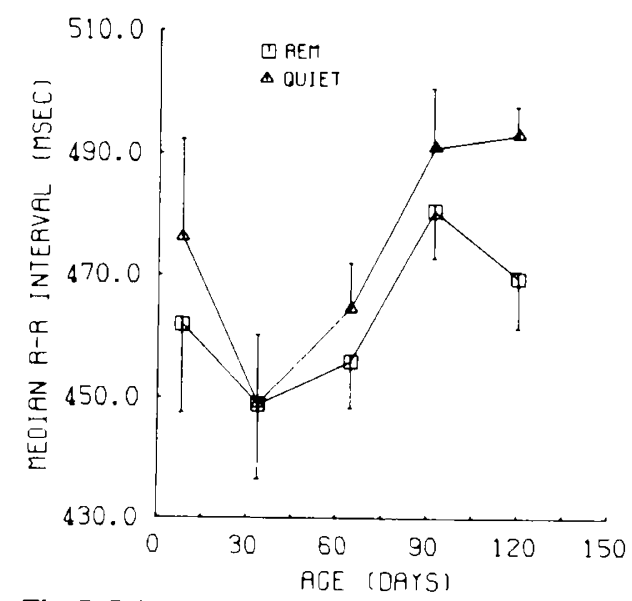

Fig. 1. The R-R interval in REM and quiet sleep as a function of age The shortest $R-R$ interval or fastest heart rate occurs at 1 month of life. The $R \cdot R$ interval is shorter in REM than in quiet sleep at each age. Mean $\pm S$.E. of all subjects are shown at each age.

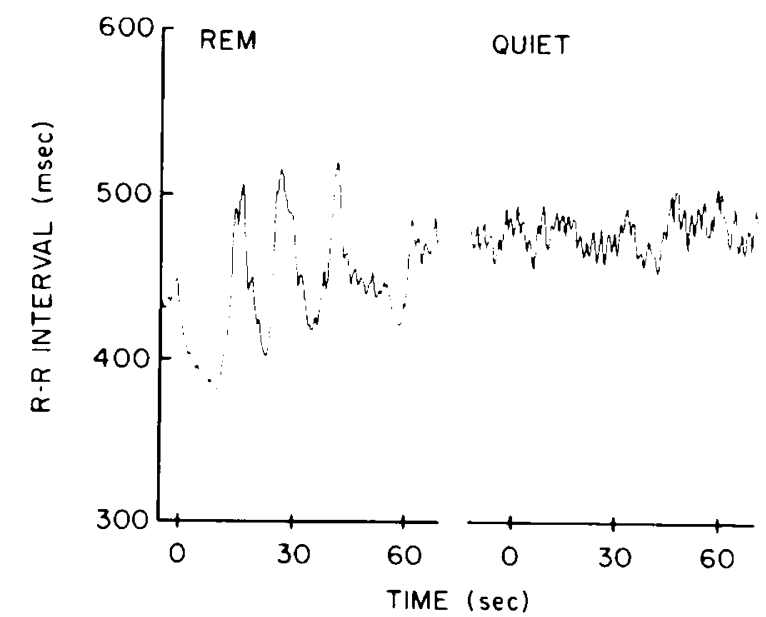

Fig. 2. The R-R interval plotted as a function of time in REM (left) and quiet (right) sleep from one study. Abscissa, approximately $60 \mathrm{sec}$ in each state. Wide swings of the R-R interval in REM sleep.

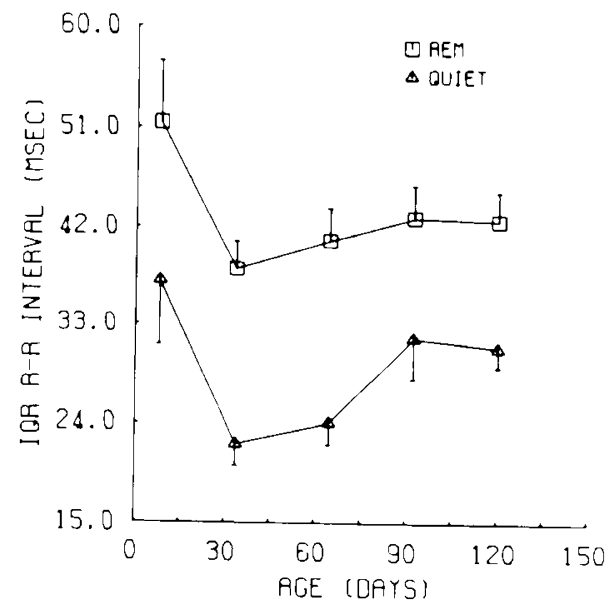

Fig. 3. The overall variability of the $R-R$ interval represented by $t$ interquartile range of the $R-R$ interval plotted against age. This variabili is significantly greater in REM than in quiet sleep at each age $(P<0.0$ paired test). Mean \pm 1 S.E. of all subjects are shown at each age.

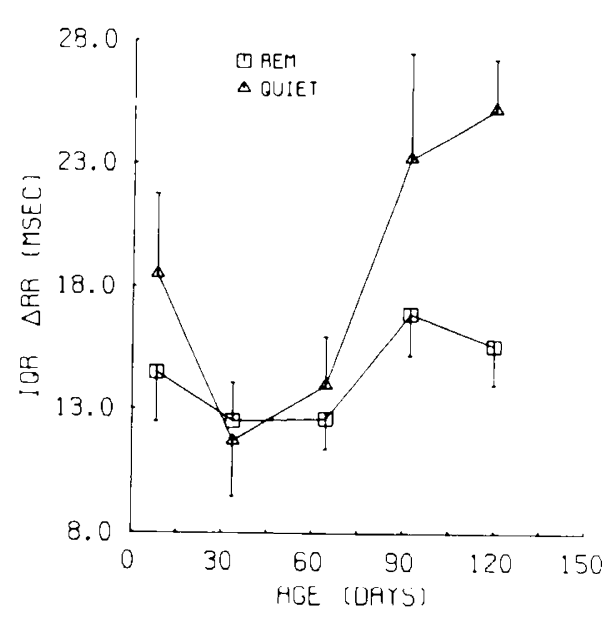

Fig. 4. The beat-to-beat variability represented by the interquartil range of $\triangle R R$ plotted against age. The beat-to-beat variability in quie sleep is significantly greater than in REM sleep during the first $2 \mathrm{wk}$ of lifi and at 3 and 4 months of age. Mean \pm S.E. of all subjects are shown a each age.

ity. Sex-related differences were not significant at any age. Al though regression analysis revealed that the $R-R$ interval tends $t$ increase from birth to 4 months of life in both sleep states. simple linear relation does not describe our data adequately. A: shown in Figure $I$, there was a decrease in the $R-R$ interval in the first month of life which contrasted with the general trend tic increase beyond one month of age. In fact, polynomial regressior analysis showed a significant third-order regression coefficient in both sleep states. In addition, the highest rate of change of the $R$ $\mathrm{R}$ interval occurred between 2 and 3 months of age.

In 54 of the 78 studies performed, the median $R-R$ interval was shorter in REM than in quiet sleep $(P<0.01$; sign test). In addition, the mean $R-R$ interval was shorter in REM than in quiet sleep at each age (Fig. 1): however, the variance of the mean was large, and statistical significance was only present in the first $2 \mathrm{wk}$ and at 2 and 4 months of life.

Figure 2 shows a typical plot of the R-R interval as a function of time. Note that: (1) the R-R interval is variable in both sleep states in normal infants; (2) the overall variability of the $R-R$ interval is greater in REM than in quiet sleep. In fact, the interquartile range of the $R-R$ interval was significantly greater in REM than in quiet sleep at each age (Students $t$ test. $P<0.01$; Fig. 3). Regression analysis shows that there is no significant 
near trend of the overall variability with age. but significant hird-order regression coefficients were present in both sleep states. Ainimal variability occurred at 1 month of age and coincided ith the time of the shortest R-R interval. The largest overall ariability occurred during the first $2 \mathrm{wk}$ of age.

The beat-to-beat variability of the $R-R$ interval was significantly reater $(P<0.05)$ in quiet than in REM sleep at all ages except at month (Fig. 4). In addition, a significant majority of studies (44 $f 78$ ) had a larger beat-to-beat variability in quiet than in REM leep (sign test, $P<0.05)$. Regression analysis of the interquartile ange of $\triangle R R$ against age revealed a parallel maturational trend o that of the median $R-R$ interval. There was a positive linear rend in both sleep states. However, in both sleep states, the elation was better described by a third-order regression.

\section{IDSC USSION}

Our results indicate that the $R-R$ interval, the overall variability, nd the beat-to-beat variability of the $R-R$ interval in $R E M$ are lifferent from those in quiet sleep. The overall variability, howver. showed the least overlap between REM and yuiet sleep: ience. of the three parameters we analyzed. the overall variability $s$ the best descriptor of sleep state. The larger overall variability If the $R-R$ interval in REM sleep probably results, at least in part. rom phasic alterations in sympathetic and parasympathetic activty which characterizes REM sleep (2.11, 13). In addition. flucuations in blood pressure during REM sleep $(2,11.19)$ may lead of further swings in $R-R$ interval.

The mean $R-R$ interval was smaller. i.e. the heart rate was aster in REM than in quiet sleep in our infants. Thus, our results ire similar to those of studies by others in human newborns (16) and adults (11. 19) in whom the R-R interval was in general. lightly decreased in REM sleep. Experiments on adult cats have demonstrated a dramatic decrease in $R-R$ interval in REM sleep Juring actual REM $s(2)$. This phasic decrease in $R-R$ interval was found to be the result of a phasic increase in sympathetic and decrease in parasympathetic activity to the heart (2.5). However, an actual tonic increase in $R-R$ interval has been noted during those intervals when the electroencephalogram. electromyogram. and respiration are consistent with REM sleep, but actual eye movements are not present. It is possible, therefore, that averaging the $R-R$ interval over a whole REM cycle. as in our infants. obscures the various periodic changes in the $R-R$ interval and narrows the differences between REM and quiet sleep. This nonuniformity of autonomic influences in REM sleep is consistent with other evidence that REM sleep is more than one sleep state (18)

The functional basis of the decrease in the $R-R$ interval in our infants during REM sleep is unknown. Because peripheral vasodilatation and decrease in venous return occurs in REM sleep (13). a decrease in the $R-R$ interval (increase in the heart rate) may be a homeostatic mechanism to maintain cardiac output (11. 13).

We have shown recently that beat-to-beat variability varies inversely with heart rate (14). In these studies, the R-R interval is linearly related to the instantaneous heat-to-beat variability, and the $\triangle R R$ increases one msec for each 10 -msec increase of $R-R$ (14). On the basis of this relationship, one would expect a smaller beat-to-beat variability in REM than in quiet sleep because the $\mathrm{R}-\mathrm{R}$ interval is smaller in REM sleep. However, the differences we observed in the beat-to-beat variability between REM and quiet sleep in the present study cannot be entirely explained by differences in the $R-R$ interval itself. For example. our 3-monthold infants show a difference in the $\triangle R R$ of about $7 \mathrm{msec}$ when the differences in the $\mathrm{R}-\mathrm{R}$ interval is approximately $10 \mathrm{msec}$. Because the magnitude of $\triangle R R$ is, to a large extent, due to respiratory sinus arrhythmia (8). larger sinus arrhythmia in quiet sleep in these infants. similar to that described in adults (3), could result in a larger $\triangle R R$.

Previous workers have suggested that the postnatal development of the $R-R$ interval and $R-R$ interval variability is divided into 3 distinct periods: neonatal. 1 to 3 months of age. and older infancy (7). Our data which are described by a third-order regression function are consistent with this view. The postnatal development of the $\triangle R R$ which has not been described previously follows the same pattern of development as that of the heart rate and overall variability of the heart rate.

\section{REIEREN(HS ANI) N(OTIS}

1. Anders. T. Imde, R.. and Parmelee. F.. A manual of standardaed termmology. techniques and criteria for scoring of states of seep and wakefulness in new born infants. (BRI Publicatums. 1.0s Angeles. 1971)

2. Batust. $W$. and Bohnert. B. The regulatuon of heart rate durng sleep. t.xp. Bratn Res. - 169) $(196 \%)$.

3. Bond. W ( .. Bohs ( . L hev. J.. Jr., and Woll. S.: Rhythmic heart rate variabilat (sinu arrhythma) retated to stages of sleep. Cond. Retlex. S: $48(1973$ )

4. Dittichwa. J.: The development of sleep in infancy. J. Appl. Phrsol. 21: 124. (1) (1) (n) )

5 Guard, M. Manclat. (i. Kumazatua. T. Baccelli. (j.. and Zanchelu, A Iflled of cardiac denervation on blood pressure and heart rate during naturat sleep in the cat. (ardionase Res.. ? $265(196 x)$.

6. Haddad. (i. (i., Makza. N. M. Detendinı. R.. Blanc, W. A. D)riscoll. J. M Ipstein. M. A. I.. Epsten. R. A., and Mellins. R. B.: Congential failuse of automatic control of ventilation. gastrointestinal motility and heart rate. Medwine (Battimere). $5: 517(1978)$

7. Harper. R. M. Hoppentrouwers. T., Sterman. M. B.. Mc(inty. D). J.. and Hodgman. J.: Polvgraphe studies of normal infants during the tirs sx month of life. 1. Heart rate and varlability as a function of state. Pediatr. Res.. 111: 4/5 (1976).

x. Harper. R. M. Walter. 1). (). I.eake. B.. Hoffman. H. J.. Sieck. (i. ( .. Sternam M. B. Hoppenbrouners. T.. and Hodgman. J : Development of snus arrhyth mia during sleeping and waking states in normal infants. Sleep. 1: $3.3(197 x)$.

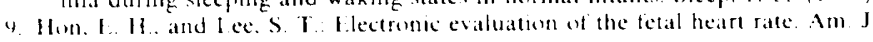
Obutet (ivnecol. $\mathrm{r}^{-2} \times 14(1963)$

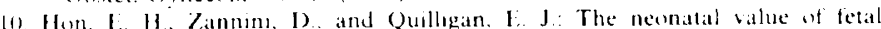
monituring Am J Obstet (iynecol. 12:2. 50) (1975).

11. Khatri. I. M.. and Fress, I. 1). Hemodynamic changes during sleep J. Appl

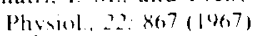

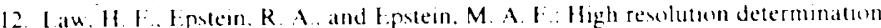
of the RR interval. Am J Phoviol. 2in: $844(1979)$

13. Manciat (i. Baccelli. (i. Adams, D) B., and Zanchetti. A.: Vasomotor regulatom durng sleep in the cat Am. J. Physiol. 22f): 1086 (1976).

14. Mat/a. N M.. I poteln. M A.. Maddad. (i. (;. Latu. H. S. Kat/. J. S. Mellim R. B and tostein. R. A : Dependence of heart rate variability on motantaneous heart rate in sleep. Pediatr. Res (Abstract). 11:395 (1977).

15. Miller. F. ( . and Paul. R. H.: Intrapartum tetal heart rate momtoring. (Chn (Obstet. (iynecol. 2l: $501(1978)$

16. Prechtl H \& R Aksama, Y. Zmkin, P... and (irant, D) $K$. Polygraphic studes of the full-term newhorn. I. Technical aspects and yualitative analwis In: $R$ Machesth. M. Bax: Studies in infancy (Clinces in Deselopmental Medicine) Vol 27. pp. I 21 ifteinemann Medical. London. I96

17 Renou. P.. (hang. A. Anderson. 1.. and Wood. ( . Controlled tral of tetal intensive care Am Jobstet (ivnecol.. /26):470)(1976).

18. Schulte, F. J.. Busse, ( .. and Iichhorn. W.: Rapid eve movement, motoneurone inhibitum and apneic spelts in preterm infants. Pediatr. Res. 111: $7169(1977)$.

19. Snvder. F. Hohoun. J. A. Morrison. D). F.. and (ioldfrank. F.. (hanges in respiration. heart rate. and systolic blond pressure in human sleep. J Appl. Phivil. II): 417 (1904)

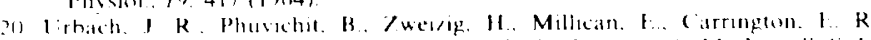
l.weland. M. Willams. J M.. Lambert, K. L... Duncan, A M.. Faticll. S. I simons $p o$ and Spurgeon. 1. 1. Instantaneous heart-rate patterns in newborn intants. Am. J. Obstet (ivnecol., $123: 965(196,5)$

21. Reyuests for reprints should he addressed to: (i. (i. Haddad, M.1).. Pediatric Pulmonary Divison. Columbiat Preshyterian Medical (enter, 6.22 West losth Sireet. New York. N. Y. 1131132 (11SA).

22. This research was supported by National Institutes of Health (irants HI) $11 \times 297$

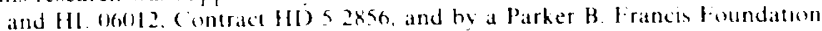
fillowstip.

23. Recesved for publication February 27. 1479

24. Accepted fir pubiciation september 26. 1979. 